\title{
CoN - lifeline for patients, noose for healthcare providers?
}

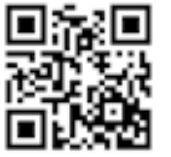

You could liken the new Certificate of Need (CoN) law to a brightly coloured centipede, signalling hope of better access to healthcare for millions but work endangerment to private specialists, hospital groupings, GPs and other healthcare professional groupings.

In spite of the 12 years it took to hatch suddenly emerging to spread hope, alarm and confusion in equal measures - full maturity is now expected only well beyond two years. National Health Director-General Precious Matsoso's chief entomologists (read: state law advisors) have examined the creature and concluded that it will almost certainly curl up and sulk if overloaded with the logistical demands of a 1 April 2016 implementation deadline (70 000 healthcare establishments to have applied for a CoN by then, not to mention tens of thousands of healthcare providers consulted via their groupings to inform regulations before they are actually drafted and published for comment). That's also the date (which they're now trying to de-proclaim via President Zuma's office) by which every single healthcare provider in the country would have had to apply to Matsoso for a $\mathrm{CoN}$, whether they're setting up, modifying or buying a health establishment, increasing bed numbers, acquiring expensive technology, or simply continuing to practise where they are. The legal animal (hatched as provisions 36 - 40 of the National Health Act) has a noble purpose - to meet the government's constitutional obligations of progressive and universal access to healthcare - but it's got lots of legs and a vicious (some say unavoidably necessary) bite: five years' imprisonment and/or a fine for non-compliance. That it's in hibernation until resuscitated 'as is', with a reproclamation that enables a later, more pragmatic implementation date, is merely a temporary respite.

\section{Trust us, we won't let this creature bite}

Speak to its architects and prospective implementers, and they'll try to reassure you that the increasingly vocal private healthcare provider groups are suffering from chilopodophobia (an irrational fear of centipedes). Privately, some may even whis- per that a scary and tropically sized centipede is necessary to bend the will of private healthcare providers long accustomed to the hugely skewed access to healthcare that too many of us regard as the norm. They solemnly promise that the animal they've engineered is remotely controlled; they'll not allow it to bite (e.g. no practices will be uprooted via denial of a certificate). Speak to the objectors/detractors (in descending order of decibels: specialists, hospital groupings, allied health professionals, GPs), and they'll tell you that the creature, as legally constituted, is a formidably large, red-lined creepy-crawly on steroids, with undeniable pincers able to inflict painful and potentially debilitating wounds. Sure, a few legs are being mended, but the creature's alive and well - and only 'squashable' in the courts, probably the Constitutional Court. While they 'fully support' equitable access to healthcare, they have a serious problem with the 'deeply flawed' instrument being used. Putting back its implementation date is 'mere tinkering. This makes it almost certain that the real battle, led by the specialists and hospital groupings, will play out in the courts. It's here that the government's attempt to deal with the mismatch between the geographical placement of critically scarce human healthcare resources and the geographical spread of our quadruple burden of diseases will be picked apart, segment by segment, under the unrelenting spotlight of section 27 of the Constitution. Do the $\mathrm{CoN}$ provisions meet the government's constitutional obligation to adopt 'reasonable' legislative and other measures aimed at ensuring progressive, universal access to healthcare? Or do they collectively flout so many other constitutional rights (freedom of movement, trade and competition, access to information) as to warrant amending or striking down? Stir in our healthcare human-resource crisis ...

\section{Will it do more harm than good?}

It's a fascinating debate, but one that will carry little weight with healthcare professionals overwhelmed by a harsh public sector work environment and contemplating the seemingly welcome relief of a move to the local private sector. The CoN could simply add to the steady annual tally of healthcare providers heading overseas, many never to return, and prompt a dramatic reduction in the number of young people wanting to enter the healthcare professions, with dire national implications. Those are potent unintended consequences that would fundamentally undermine the law's intentions. As usual, whenever there's potential to make a quick and nasty buck in the public sector, this law will also create fertile ground for bribery and corruption between officials and highstakes applicants during the certificate application process.

Izindaba spoke to Matsoso, who 'corrected' a hasty interpretation by Western Cape Health MEC Theuns Botha (Democratic Alliance) that her legal bid to reverse the CoN implementation date scrapped the entire law. She also criticised a dysfunctional Free State Health Department, whose beleaguered Health MEC Benny Malakoane (under criminal investigation for tender fraud while serving as Municipal Manager at Matjhabeng Municipality in 2007 and 2010) prematurely published CoN-related regulations - which her department is obviously now more than two years away from doing. Matsoso warned: 'This is of great concern because it creates confusion in the light of our current discussions with stakeholders.

\section{Just who stands where?}

She added: 'Nobody wants to write a law where there's a lack of understanding and conflict. We want to make sure we all understand each other from the beginning. The law is still there; all that will change is when it comes into force [this to emerge after extensive further stakeholder consultation once the proclamation is withdrawn]. Her lawyers had assured her that this had been done before. The stakeholder briefing blitz she'd begun would continue apace, with most providers 'expressing concern' (her words) over sections 36 and 40 (abbreviated in the box on the next page and discussed above). She said the South African Medical Association (SAMA), in particular, wanted amendments to both provisions and the scrapping of CoN limitations on individuals. So far optometrists, dentists and occupational health practitioners (OHPs) had indicated willingness to work with her, the OHPs needing clarity on how 
industrial clinics would be certified. One helpful suggestion, which she was 'taking very seriously', was to 'use a more staggered approach' in implementing the law. Labour organisations were backing her, but the Hospital Association of South Africa and the South African Private Practitioners Forum did not want the CoN to apply to them 'at all'. SAMA (17 000 members) had provided her with a list of all GPs. 'Now we just have to agree on a date to thrash it all out with the GPs.' She said consultative processes were being tailored to each healthcare professional grouping, while she intended asking all relevant statutory bodies to help by providing databases to facilitate licensing (a concurrent task of the Office for Healthcare Standards Compliance (OHSC), which will be integral part of the CoN process) - plus certification. The OHSC had completed its initial inspection work in setting minimum norms and standards for primary health care facilities in the public sector, and would now turn its attention to the private sector.

Asked whether she considered her CoN deadline proclamation-scrapping a setback, Matsoso replied: 'When you consult people and take their concerns into account, you

\section{A snapshot of the Certificate of Need}

A CoN will be required for anyone:

- Establishing, constructing, modifying or acquiring a health establishment or agency

- Increasing the number of beds in, or acquiring prescribed health technology at, a health establishment or health agency

- Providing 'prescribed' health services, or continuing to operate a health establishment or health agency, after the expiration of 24 months from the date at which the relevant addition to the Act took effect (1 April 2014 - this deadline is now up for change).

The Act requires the Director-General of Health to apply her/his mind to several requirements before issuing a certificate. These include consistency of health services, development in terms of planning, equitable distribution and rationalisation of services and resources (including existing public and private facilities in an area, correcting racial, gender, economic and geographical imbalances, and financial viability), taking into account the demographic and epidemiological characteristics of the population to be served, plus furthering the Employment Equity Act within emerging small, medium and micro-enterprises.

can't call that a setback - that's very naive. We can work collectively. The private sector is a resource for this country. If you want to respond to the burden of disease you have to take into account all your resources.'

Just how she and her political masters do that, and whether they and the private sector can work out an amicable solution, will either improve or worsen healthcare for us all.

\section{Chris Bateman}

chrisb@hmpg.co.za

S Afr Med J 2014;104(9):597-598.

DOI:10.7196/SAMJ.8774 